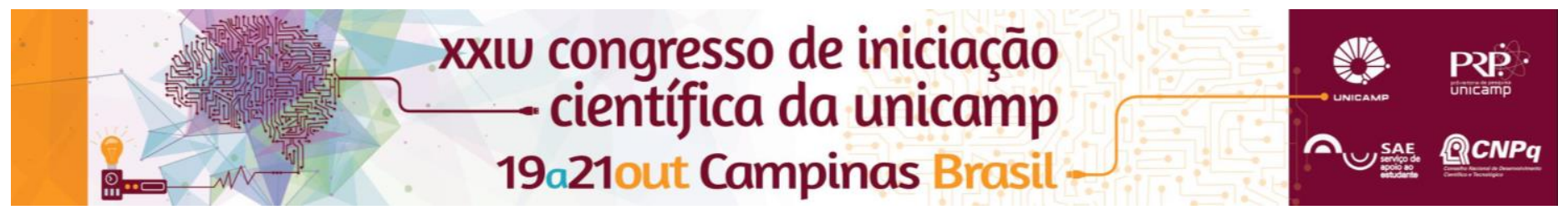

\title{
Influência da taxa de inoculação no processo de fermentação na medida de unidades de amargor da cerveja.
}

\author{
Priscila Ferreira Tavares*, Alexandre M. V. Leme, Flávio Luis Schmidt.
}

\begin{abstract}
Resumo
A cerveja é a segunda bebida mais consumida quando se fala de consumo nacional. Um atributo apreciado por consumidores e característico da cerveja, é o amargor, que geralmente é medido em IBUs, unidades de amargor da cerveja. O objetivo deste projeto consiste em avaliar a alteração da medida de amargor da cerveja durante o processo de fermentação, em diferentes taxas de inoculação de levedura (Saccharomyces cervisiae, Fermentis - Safale S04). Em paralelo, foram monitoradas as alterações de composição através das análises de $\mathrm{pH}$, contagem de células, álcool e RDF (real degree fermentation), durante o processo fermentativo. Desta forma, foi identificada a variação da medida de amargor em função das taxas de inoculação do mosto, e correlacionada com os demais dados obtidos.
\end{abstract}

\section{Palavras-chave:}

Medida da amargor, fermentação, taxa de inoculação.

\section{Introdução}

Cerveja é uma bebida obtida basicamente por cinco processos, moagem do malte, mosturação, fervura, fermentação e maturação (SIQUEIRA, 2008). A mosturação é um processo que extrai os açúcares fermentescíveis e outros componentes importantes do malte. A fermentação trata-se da conversão dos açúcares do malte em cerveja e a maturação é uma fermentação secundária, na qual a levedura refina os sabores da cerveja (PALMER, 2006).

Amargor é o atributo sensorial mais importante e mais avaliado pelo consumidor. As resinas e os óleos essenciais do lúpulo são os compostos que conferem sabor amargo e aroma característico. (MEGA, 2011).

Vários fatores podem influenciar no amargor, como o tempo de ebulição durante a fermentação, absorção feita pela superfície das leveduras dos compostos de amargor e efeitos de superfície, ou ainda o tipo de levedura e o método de fermentação (PALMER, 2006).

\section{Resultados e Discussão}

Partindo de um mosto com $81 \mathrm{BU}, \mathrm{pH} 5,41$ e extrato original $11,6^{\circ}$ Plato, foram inoculadas levedura nas taxas de $10^{5}(\mathrm{~A} 5), 10^{6}(\mathrm{~A} 6)$ e $10^{7}$ (A7) células $/ \mathrm{mL}^{\circ}$ Plato, em frascos de vidro de 2 litros. Os frascos foram mantidos a $18^{\circ} \mathrm{C}$ para a fermentação durante 14 dias. Após o dia 14, a temperatura foi reduzida para $0^{\circ} \mathrm{C}$, simulando assim 0 processo de maturação.

Durante as etapas de fermentação e maturação, foram retiradas amostras para análises. A Tabela 1 apresenta os resultados de BU.

Tabela 1. Teste de Tukey da variação de BU.

\begin{tabular}{ccccccccccc}
\hline & Dia 1 & Dia 2 & Dia 3 & Dia 4 & Dia 5 & Dia 7 & Dia 9 & Dia 11 & Dia 14 & Dia 23 \\
\hline \multirow{2}{*}{ A5 } & $53,3 \pm$ & $37,7 \pm$ & $36,2 \pm$ & $37,6 \pm$ & $40,0 \pm$ & $43,7 \pm$ & $39,2 \pm$ & $40,2 \pm$ & $37,1 \pm$ & $23,9 \pm$ \\
& $1,0^{\mathrm{b}}$ & $2,7^{\mathrm{c}}$ & $0,6^{\mathrm{c}}$ & $0,7^{\mathrm{b}}$ & $1,2^{\mathrm{b}}$ & $2,2^{\mathrm{b}}$ & $0,9^{\mathrm{b}}$ & $1,8^{\mathrm{b}}$ & $1,8^{\mathrm{b}}$ & $2,4^{\mathrm{b}}$ \\
\multirow{4}{*}{ A6 } & $74,0 \pm$ & $56,4 \pm$ & $40,8 \pm$ & $45,6 \pm$ & $44,8 \pm$ & $44,7 \pm$ & $45,4 \pm$ & $49,2 \pm$ & $47,5 \pm$ & $36,0 \pm$ \\
& $0,4^{\mathrm{a}}$ & $0,3^{\mathrm{b}}$ & $1,5^{\mathrm{b}}$ & $1,3^{\mathrm{a}}$ & $1,2^{\mathrm{a}}$ & $4,3^{\mathrm{a}, \mathrm{b}}$ & $0,4^{\mathrm{a}}$ & $0,8^{\mathrm{a}}$ & $0,4^{\mathrm{a}}$ & $1,6^{\mathrm{a}}$ \\
& $73,7 \pm$ & $64,0 \pm$ & $46,2 \pm$ & $43,3 \pm$ & $43,7 \pm$ & $49,5 \pm$ & $47,1 \pm$ & $49,8 \pm$ & $46,1 \pm$ & $37,7 \pm$ \\
A7 & $2,1^{\mathrm{a}}$ & $2,0^{\mathrm{a}}$ & $1,6^{\mathrm{a}}$ & $0,9^{\mathrm{a}}$ & $2,0^{\mathrm{a}}$ & $0,3^{\mathrm{a}}$ & $1,7^{\mathrm{a}}$ & $0,8^{\mathrm{a}}$ & $0,9^{\mathrm{a}}$ & $2,7^{\mathrm{a}}$ \\
\hline
\end{tabular}

As medidas de A5 e A6 se comportaram de maneira semelhante, apresentado quedas nos dias 2 e 3 , e já atingindo no dia 4 um valor que não difere significativamente entre si $(p<0,05)$, até o dia 14. Sendo a queda dos primeiros dias de $\mathrm{A} 6$, maior que de $\mathrm{A} 5$, porém as duas chegaram ao final da fermentação (dia 14) com valores equivalentes, que não diferem entre si (Teste de Tukey).

A amostra A7, já começou o dia 1 com o menor valor de $\mathrm{BU}$ entre as amostras, apresentando diferença significativa frente as demais. A maior queda ocorreu também no dia 1 , atingindo seu valor praticamente constante no dia 2 até o fim da fermentação (dia 14), um dia antes que A5 e A6. A queda de A7 foi a maior entre as amostras (A7 70,5\%; A6 $55,6 \%$; A5 53,5\%).

No dia 23 (após a maturação), as amostras apresentam novamente uma queda significativa, sendo novamente maior a queda de A7, divergindo significativamente em relação às outras (Teste de Tukey).

A partir dos resultados da contagem de células ao longo dos processos, foi possível observar que durante o período de crescimento das leveduras, fase log, houve queda de $\mathrm{BU}$, e durante a fase estacionária, as medidas de $\mathrm{BU}$ se mantiveram constantes. A amostra A7 apresentou um pico maior de células em relação às demais amostras, o que pode estar relacionado com o fato de ter apresentado a maior queda de $\mathrm{BU}$. Quanto ao $\mathrm{pH}$, os valores variaram de 5,41 (mosto) a 4,40 (A5), 4,40 (A6) e 4,20 (A7). A quantidade de álcool ao final da maturação foi de $4,8 \%$ para as três amostras. A taxa de atenuação final foi de $64,8 \%$ (A5), $58,8 \%$ (A6) e $58,5 \%$ (A7), sendo que as amostras não diferem significativamente.

\section{Conclusões}

Pode-se observar que durante o período de fermentação a maior queda de BU ocorreu nos 5 primeiros dias. Diante dos dados apresentados conclui-se que há influência da taxa de inoculação na medida de amargor (BU), sendo um fator de controle importante para fabricação de cervejas.

\section{Agradecimentos}

Ao CNPq; à técnica e aos colegas do laboratório.

SIQUEIRA, P.B.; BOLINI, H.M.A.; MACEDO, G.A. Beer production and its effects on the presence of polyphenols. Alim. Nutr., v.19, n.4, p. 491-498, 2008 .

PALMER, J., How to brew, 2006. Brewers Publications.

MEGA, J.; NEVES, E.; ANDRADE, C., A produção de cerveja no Brasil CITINO, Vol. 1, No. 1, Outubro-Dezembro de 2011. 